\title{
A Method for Coordinating Reloading Stress \\ Relaxation Data into a Unique Curve*
}

\section{By Tetsumori SHINODA**}

\begin{abstract}
Synopsis
A method is proposed by which data from reloading stress relaxation tests performed under different conditions can be coordinated into a unique curve of the relative stress relief ratio at the final point of the $i$-th cycle of each reloading test, $\eta_{f, i}$, versus the cumulative plastic strain prior to the onset of the cycle, $\sum e_{p, i-1}$. This is possible if the value $K \equiv A_{0} E \sigma_{0}^{n-1} \tau$. $\exp (-Q \mid R T)$ for each measurement is constant, where $A_{0}, n$, and $Q$ are material constants, $E$ Young's modulus, $\tau$ the reloading interval, $\sigma_{0}$ the initial stress, and RT has the usual meaning. Some experimental results for tests on a $12 w t \%$ Cr-steel justified this proposal. Applying the unique relationship between $\eta_{f, i}$ and $\sum e_{p, i-1}$, constructed only from short interval reloading data, it is easily possible to predict long interval reloading stress relaxation behavior.
\end{abstract}

\section{Introduction}

In connection with the retightening performance of bolts in, for example, high temperature power plant, it has been necessary to device practical methods for predicting the long period reloading stress relaxation behavior of bolt materials. Draper ${ }^{1)}$ pointed out long ago the suggestive fact that a unique relationship existed between the final stress remnant after each reloading cycle and the corresponding number of cycles, for two different types of data, one obtained in shorter period/higher temperature cycle tests and the other obtained in longer period/lower temperature cycle tests, no theoretical basis for which has yet been provided. Smith et al. ${ }^{2)}$ have found that a "deterioration" in stress relaxation strength, i.e., an acceleration in stress relaxation rate, occurs in a specimen reloaded a number of times when the accumulated plastic strain attains a certain value. This deterioration phenomenon is serious for bolts because they are no longer serviceable after deterioration has occurred. Quaass ${ }^{3)}$ has proposed a graphical method for predicting reloading stress relaxation behavior, in which a diagram constructed using stress, total strain, and a temperature-time parameter was used as the basic data for prediction. Suzuki ${ }^{4}$ has developed a mathematical approach to prediction based on the argument that the stress relaxation rate in the later stage of each cycle, named "Stage II" by him, ${ }^{4,5)}$ can be prescribed in terms of so-called "time hardening" theory. Both the method due to quaass and that due to Suzuki appear to have some faults, in that the accuracy of prediction may be low due to the usage of indirect basic data from types of tests other than reloading stress relaxation tests, or the many approximations in the computing methods.

In the present paper a modified method for predic- tion is proposed, the basis of which has been reported elsewhere. ${ }^{6)}$ This method uses reloading stress relaxation data itself, but with a short reloading interval, to provide the basic data for prediction.

\section{Derivation of a Temperature Compensated Time Law for Reloading Stress Relaxation Data}

The stress relaxation rate during cycle $i$ of the cyclic reloading on a specimen can be expressed, to a first approximation, by the following equation, based on "strain hardening" theory ${ }^{4,7)}$;

$$
d \sigma / d t=-E A \sigma^{n} \varepsilon_{p}^{m}
$$

where, E: Young's modulus

$\sigma:$ the stress remnant at time $t$, which is counted from the onset of cycle $i$

$A(>0), n(>1), m(<-1)$ material constants which are here assumed to be approximately independent of the number of loading cycles.

$A$ can be further expressed as $A=A_{0} \exp (-Q / R T)$, where $A_{0}$ and $Q$ are dimensional material constants and $R T$ has the usual meaning. $\varepsilon_{p}$, the total plastic strain accumulated in the specimen at time $t$, is the only variable to change with the number of cycles, and is defined by

$$
\varepsilon_{p}=\varepsilon_{0}-\sigma / E+\sum e_{p, i-1}
$$

where, $\quad \varepsilon_{0}$ : the initial strain

$\sum e_{p, i-1}:$ the cumulative plastic strain prior to the start of cycle $i$.

Substituting Eq. (2) into Eq. (1), and then integrating Eq. (1) with respect to $t$ and $\sigma$ from the start to the end in cycle $i$, the following relationships are obtained;

$$
\int_{0}^{\eta}{ }_{f, i}(1-\eta)^{-n}[1+\alpha q+q \eta]^{p} d \eta=K\left(\sum e_{p, i-1}\right)^{-p} \ldots
$$

using the following transformations, where $\tau_{i}, \sigma_{\mathbf{0}}$ and $\sigma_{f, i}$ are the period of cycle $i$, the initial stress, and the stress remnant at the end of cycle $i$, respectively;

$$
\begin{aligned}
\eta & \equiv\left(\sigma_{0}-\sigma\right) / \sigma_{0} \quad(0<\eta<1) \\
p & \equiv-m \quad(m>1) \\
q & \equiv \sigma_{0} / E\left(\sum e_{p, i-1}\right) \quad(0<q<1) \\
\alpha & \equiv E \varepsilon_{0} \sigma_{0}-1 \quad(\alpha \geq 0) \\
\eta_{f, i} & \equiv \eta \text { at } t=\tau_{i} \equiv\left(\sigma_{0}-\sigma_{f, i}\right) / \sigma_{0}
\end{aligned}
$$

and

* Received October 5, 1979.

** Hitachi Research Laboratories, Hitachi Ltd., Saiwai-cho, Hitachi 316. Now dispatched to Research Laboratory of Precision, Machinery \& Electronics, Tokyo Institute of Technology, Nagatsuda, Midori-ku, Yokohama 227. 


$$
K \equiv A E \sigma_{0}^{n-1} \tau_{i} \equiv A_{0} \exp (-Q / R T) E \sigma_{0}^{n-1} \tau_{i} \ldots \ldots(5)
$$

The left hand side of Eq. (3) is uniquely dependent on $\sigma_{f, i}$, and the right hand side is a unique function of $\sum e_{p, i-1}$ if $K$ can be put as a constant, regarding $\tau_{i}$ as being constant for a given combination of test variables $\sigma_{0}$ and $T$ in Eq. (5). In other words, Eq (3) implies the existence of a " temperature compensated time" law in reloading data, similar to the Larson-Miller relationship in creep or creep rupture, and provides a theoretical basis for the experimental results of Draper mentioned above. Thus it is possible in principle to predict the value of $\sigma_{f, i}$ for any cycle of a reloading stress relaxation test, however long the period of the cycle is, based on a $\eta_{f, i} v s . \sum e_{p, i-1}$ curve which can be constructed from short period reloading test data only. It should be noted here that we need only to know the stress remnant at the end of a cycle, since the tightening stress of a bolt needs only to be kept above a certain critical level during the bolt tightening.

\section{Application and Discussion}

Table 1 shows the results of reloading tests on two heats (A and B) of a $12 \mathrm{wt} \% \mathrm{Cr}$ heat resisting steel originally obtained for somewhat different purposes ${ }^{6,8)}$ than for checking the method proposed here. In this table $\sum \tau_{i}$ is the summation of the stress peroids before cycle $i$, from which it is possible to compute the period of each cycle. Figures 1(a), (b) and (c) show the variation of $\eta_{f, i}$ with $\sum \tau_{i} \sum e_{p, i-1}$, and $\log \sum e_{p, i-1}$, respectively.

It can be seen that the curve for the $600^{\circ} \mathrm{C} / 140 \mathrm{~h}$ cycle test and that for the $550^{\circ} \mathrm{C} / 800 \mathrm{~h}$ cycle test are separate from each other in Fig. 1(a), while the data points for both the tests lie close to a single curve of $\eta_{f, i} v s . \sum e_{p, i-1}$ (Curve 2) in Fig. 1(b), as well as on a single curve of $\eta_{f, i}$ vs. $\log \sum e_{p, i-1}$ in Fig. 1(c). Figure 2 shows the variation of $\eta_{f, i}$ with $\sum e_{p, i}$ (N.B. not $\left.\sum e_{p, i-1}\right)$, demonstrating the existence of a similar unique relation between these quantities to that in Fig. 1(b).

The good agreement found in the data for the $600^{\circ} \mathrm{C} / 140 \mathrm{~h}$ and $550^{\circ} \mathrm{C} / 800 \mathrm{~h}$ tests shown in Figs. 1 (b), 1(c) and 2 was mainly chance, at least in this case. However this agreement would seem to indicate some justification for the existence of the temperature compensated time law deduced in the preceding section, since the value of $Q$ computed from Eq. (5), based on the $600^{\circ} \mathrm{C} / 140 \mathrm{~h}$ and $550^{\circ} \mathrm{D} / 800 \mathrm{~h}$ agreement, was reasonable, as shown below. The disagreement between the data for the $550^{\circ} \mathrm{C} / 800 \mathrm{~h}$ and $550^{\circ} \mathrm{C} / 140 \mathrm{~h}$ tests, or between the data for the $600^{\circ} \mathrm{C} / 140 \mathrm{~h}$ and $550^{\circ} \mathrm{C} / 140 \mathrm{~h}$ tests would seem also to support this argument, since the value of $K$ for each test above was never identical, as can be seen from Eq. (5). In this point there is a problem to be considered. In order to deduce the relationship of Eq. (3), Eq. (1) was assumed, based on strain hardening theory. Therefore the value of $\eta_{f, i}$ estimated from Eq. (3), $\eta_{f, i}$ (cal), would be rather different from the experimental value, $\eta_{f, i}$ (obs), becoming more
Table 1. Summary of results of reloading stress relaxation tests on TAF steel.*

\begin{tabular}{|c|c|c|c|c|}
\hline Tests & Remarks & $\eta_{f}^{* *}$ & $\sum e_{\mathrm{v}}(\%)$ & $\sum \tau(\mathrm{h})$ \\
\hline \multirow{7}{*}{$\begin{array}{l}550^{\circ} \mathrm{C} / \\
140 \mathrm{~h} \\
\text { cycle test }\end{array}$} & \multirow{7}{*}{$\begin{array}{l}\text { Material B, } \\
\text { Initial stress : } \\
30 \mathrm{kgf} / \mathrm{mm}^{2}\end{array}$} & 1 & 0.015 & 0 \\
\hline & & 0.433 & 0.103 & 142.8 \\
\hline & & 0.347 & 0.174 & 281.1 \\
\hline & & 0.293 & 0.234 & 429.9 \\
\hline & & 0.287 & 0.292 & 580.0 \\
\hline & & 0.250 & 0.343 & 719.6 \\
\hline & & 0.207 & 0.385 & 854.6 \\
\hline \multirow{7}{*}{$\begin{array}{l}600^{\circ} \mathrm{C} / \\
140 \mathrm{~h} \\
\text { cycle test }\end{array}$} & \multirow{7}{*}{$\begin{array}{l}\text { Material B, } \\
\text { Initial stress : } \\
25 \mathrm{kgf} / \mathrm{mm}^{2}\end{array}$} & 1 & 0.015 & 0 \\
\hline & & 0.548 & 0.132 & 142.2 \\
\hline & & 0.440 & 0.224 & 279.9 \\
\hline & & 0.414 & 0.304 & 430.6 \\
\hline & & 0.404 & 0.382 & 581.1 \\
\hline & & 0.376 & 0.460 & 721.1 \\
\hline & & 0.368 & 0.532 & 883.1 \\
\hline \multirow{5}{*}{$\begin{array}{l}550^{\circ} \mathrm{C} / \\
800 \mathrm{~h} \\
\text { cycle test }\end{array}$} & \multirow{5}{*}{$\begin{array}{l}\text { Material A, } \\
\text { Initial stress : } \\
30 \mathrm{kgf} / \mathrm{mm}^{2} \\
\text { (Step down } \\
\text { method) }\end{array}$} & 1 & 0.015 & $\sim 0$ \\
\hline & & 0.550 & 0.128 & 600 \\
\hline & & 0.453 & 0.221 & 1430 \\
\hline & & 0.400 & 0.303 & 2280 \\
\hline & & 0.387 & 0.381 & 3450 \\
\hline \multirow{3}{*}{$\begin{array}{l}550^{\circ} \mathrm{C} / \\
250 \mathrm{~h} \\
\text { cycle test }\end{array}$} & \multirow{3}{*}{$\begin{array}{l}\text { Material A, } \\
\text { Initial stress : } \\
30 \mathrm{kgf} / \mathrm{mm}^{2}\end{array}$} & 1 & 0.015 & $\sim 0$ \\
\hline & & 0.345 & 0.105 & 216 \\
\hline & & 0.315 & 0.169 & 479 \\
\hline \multirow{3}{*}{$\begin{array}{l}575^{\circ} \mathrm{C} / \\
175 \sim 300 \mathrm{~h} \\
\text { cycle test }\end{array}$} & \multirow{3}{*}{ Ditto } & 1 & 0.030 & $\sim 0$ \\
\hline & & 0.478 & 0.190 & 175 \\
\hline & & 0.465 & 0.295 & 496 \\
\hline \multirow{3}{*}{$\begin{array}{l}600^{\circ} \mathrm{C} / \\
150 \sim 300 \mathrm{~h} \\
\text { cycle test }\end{array}$} & \multirow{3}{*}{ Ditto } & 1 & 0.060 & $\sim 0$ \\
\hline & & 0.538 & 0.280 & 149 \\
\hline & & 0.538 & 0.407 & 600 \\
\hline
\end{tabular}

TAF steel is composed of $0.2 \mathrm{C}-11 \mathrm{Cr}-\mathrm{Mo}-1 / 5 \mathrm{~W}-1 / 5 \mathrm{Nb}-0.02 \mathrm{~B}$ in $\mathrm{wt} \%$, and heat treated as $1150^{\circ} \mathrm{C}$, O.Q. $\rightarrow 700^{\circ} \mathrm{C}$, A.C.

** $\eta_{f}$ is the relative stress relief: $\left(\sigma_{0}-\sigma_{f}\right) / \sigma_{0}$, where $\sigma_{0}$ : initial stress, $\sigma_{f}$ : final residual stress, of the cycle.

different the greater the number of reloading cycles, because the stress relaxation rate during a reloading cycle estimated from Eq. (1) is not always in good agreement with experimental values. ${ }^{4,6,8)}$ The reason why the temperature compensated time law predicted from Eq. (3) nevertheless holds, as above, is possively because the relative error in $\left(\eta_{f, i}(\mathrm{obs})-\eta_{f, i}(\mathrm{cal})\right) /$ $\eta_{f, i}$ (obs) was almost constant during each reloading cycle test having the same value of $K$. Putting $\eta_{f, i}$ $(\mathrm{cal})=F\left(K, \sum e_{p, i-1}\right)$, it follows that $\eta_{f, i}(\mathrm{obs}) \cong$ $F\left(K, \sum e_{p, i-1}\right) /(1-$ const. $)$, so that a temperature compensated time law could hold even for the $\eta_{f, i}$ (obs) vs. $\sum e_{p, i-1}$ data.

In Fig. 1(b) the data for the $550^{\circ} \mathrm{C} / 250 \mathrm{~h}$ cycle test, with $\sigma_{0}$ equal to $30 \mathrm{kgf} / \mathrm{mm}^{2}(\sim 300 \mathrm{MPa})$, is located a little apart from and to the left of Curve 1, which is for the $550^{\circ} \mathrm{C} / 140 \mathrm{~h}$ cycle test, using the same initial stress. This seems somewhat anomlous in view of Eq. (3), from which it is to be expected that the $550^{\circ} \mathrm{C} / 250 \mathrm{~h}$ data will be located to the right of Curve 1 , since the value of $K$ is greater than that in Curve 

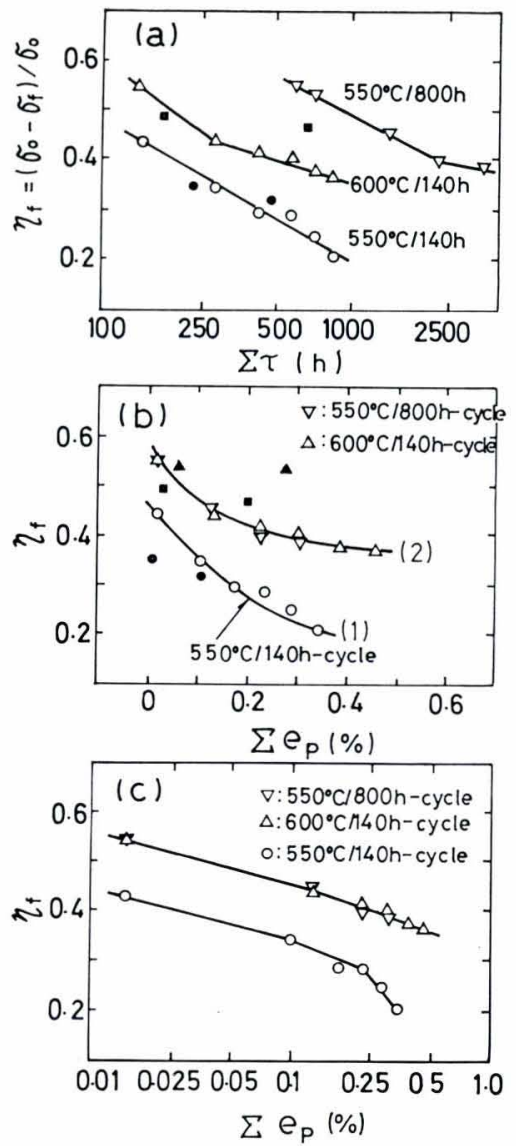

-: $550^{\circ} \mathrm{C} / 250 \mathrm{~h}$ cycle test

ש: $575^{\circ} \mathrm{C} / 175 \sim 300 \mathrm{~h}$ cycle test

A : $600^{\circ} \mathrm{C} / 150 \sim 500 \mathrm{~h}$ cycle test

Fig. 1. Relationships between the relative stress relief $\eta_{f}$, the cumulative time $\sum t$, and the cumulative plastic strain $\sum e_{p}$, for reloading stress relaxation tests on TAF steel.

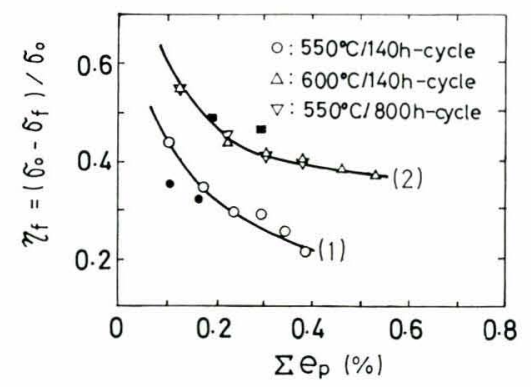

Fig. 2. Relationship between $\eta_{f, i}$ and $\sum e_{p, i}\left(\mathcal{N} . B\right.$. not $\eta_{f, i}$ vs. $\sum e_{p, i-1}$ in Fig. 1(b)), where $\sum e_{p, i}$ is the cumulative strain up to the end of the $i$-th cycle.

1. This anomaly may result from the scatter in stress relaxation strength from specimen to specimen, which is characteristic of this type of steel. ${ }^{6}$ )

The data for the $600^{\circ} \mathrm{C} / 150 \sim 500 \mathrm{~h}$ and $575^{\circ} \mathrm{C} /$ $175 \sim 300 \mathrm{~h}$ tests, marked $\boldsymbol{\Delta}$ and respectively in Fig. 1, cannot be directly compared with Curves 1 and 2 in (b) of this figure, because the values of $\tau_{i}$, and thus of $K$, are not constant in the former but are constant in the latter. However, the fact that the data for the $575^{\circ} \mathrm{C} / 175 \sim 300 \mathrm{~h}$ test intersects Curve 2 in Fig. 1 (b) suggests that the period $\tau_{i}$ of a constant $K$ test at $575^{\circ} \mathrm{C}$ with a $K$ identical with that in
Table 2. Values of the constant $Q$ used in the temperature-compensated time relationship.

\begin{tabular}{c|c|c}
\hline Materials & Comparative testing conditions & $Q(\mathrm{kcal} / \mathrm{mol})$ \\
\hline TAF steel & $\begin{array}{l}550^{\circ} \mathrm{C} / 800 \mathrm{~h} / \sigma_{0}=30 \mathrm{kgf} / \mathrm{mm}^{2}: \\
600^{\circ} \mathrm{C} / 140 \mathrm{~h} / \sigma_{0}=25 \mathrm{kgf} / \mathrm{mm}^{2}\end{array}$ & $\begin{array}{l}98.2(n=10) \\
78.0(n=6)\end{array}$ \\
\cline { 1 - 2 } $\begin{array}{c}\mathrm{Cr}-\mathrm{Mo}-\mathrm{V} \\
\text { steel }\end{array}$ & $\begin{array}{l}625^{\circ} \mathrm{C} / 546 \mathrm{~h} / \varepsilon_{0}=0.15 \% \\
650^{\circ} \mathrm{C} / 157 \mathrm{~h} / \varepsilon_{0}=0.15 \%\end{array}$ & $78.5^{* *}$ \\
\cline { 1 - 2 } $\begin{array}{c}12 \% \mathrm{Cr} \\
\text { steel* }\end{array}$ & $\begin{array}{l}650^{\circ} \mathrm{C} / 178 \mathrm{~h} / \varepsilon_{0}=0.15 \% \\
625^{\circ} \mathrm{C} / 1095 \mathrm{~h} / \varepsilon_{0}=0.15 \%\end{array}$ & $94.0^{* *}$ \\
\hline
\end{tabular}

* from Draper (See Ref. 1)).

** These values were calculated by regarding $\sigma_{0}$ as a constant.

Curve 2 lies within the range 170 to $300 \mathrm{~h}$.

To confirm this it is necessary to know the values of $Q, n$, and $E$ associated with Eq. (5). Assuming $A_{0}$ to be a constant, $Q$ can be calculated from Eq. (5) as

$$
\begin{aligned}
Q= & 2.303 R\left[\operatorname { l o g } \left(\tau_{i 1} E_{1} / \tau_{i 2} E_{2}\right.\right. \\
& \left.+(n-1) \cdot \log \left(\sigma_{01} / \sigma_{02}\right)\right] /\left(1 / T_{1}-1 / T_{2}\right)
\end{aligned}
$$

For Curve 2 in Fig. $1(\mathrm{~b})$, putting $\tau_{i 1} \simeq 800 \mathrm{~h}, T_{1}=$ $823 \mathrm{~K}, \sigma_{01}=30 \mathrm{kgf} / \mathrm{mm}^{2}(300 \mathrm{MPa})$, and $\tau_{i 2} \simeq 140 \mathrm{~h}$, $T_{2}=893 \mathrm{~K}, \sigma_{02}=25 \mathrm{kgf} / \mathrm{mm}^{2}(250 \mathrm{MPa})$, with $E_{1}=$ $E_{2}$, the value for $Q$ can be computed to be $\sim 78.0$ $\mathrm{kcal} / \mathrm{mol}(326.4 \mathrm{~kJ} / \mathrm{mol})$ if $n=6$ or $\sim 98.2 \mathrm{kcal} / \mathrm{mol}$ $(410.9 \mathrm{~kJ} / \mathrm{mol})$ if $n=10$. These magnitudes of $Q$ appear to be reasonable compared with magnitude of the apparent activation energy for creep in heat resisting steels. ${ }^{9)} \quad \tau_{i}$ for a constant $K$ reloading cycle test at $575^{\circ} \mathrm{C}$ can then be estimated to be $\sim 190 \mathrm{~h}$ using the relationship $\tau_{i} \simeq \exp \left(-Q / T R_{1}\right) \cdot \tau_{i 1} / \exp (-Q /$ $R \times 848)$, derived from Eq. (4), together with the values $Q \simeq 80 \mathrm{kcal} / \mathrm{mol}(334.7 \mathrm{~kJ} / \mathrm{mol}), T_{1}=823 \mathrm{~K}$ and $\tau_{i 1} \simeq 800 \mathrm{~h}$. This magnitude of $190 \mathrm{~h}$ is within the range of 170 to $300 \mathrm{~h}$ estimated above, providing a further justification of the present theoretical deduction. Table 2 summarises the values of $Q$ obtained from reloading tests, including those of Draper. ${ }^{1)}$ It can be seen that the values of $Q$ computed from Draper's results, with the assumption $E_{1} \simeq E_{2}$ and $\sigma_{01} \simeq_{02}$, are comparable to the value of $Q$ obtained above.

A point to be noted with respect to Draper's results is that the unique relation between data from longer period/lower temperature tests and that from short period/higher temperature tests held even in the range of cycles where the specimen deterioration was appreciable. This suggests the possibility that deterioration may initiate at a constant value of $\sum e_{p}$, even in reloading stress relaxation tests under different conditions, so long as the values of $K$ are kept constant.

\section{Conclusions}

(1) Reloading stress relaxation measured under various conditions with a constant $K$ (which is defined by the equation

$$
K \equiv A_{0} E \sigma^{n-1} \tau \operatorname{xep}(-Q / R T)
$$


where, $A_{0}, n, Q:$ material constants

$E$ : Young's modulus

$\tau:$ the period of a cycle

$\sigma_{0}:$ the initial stress

$R T$ : the usual meaning

can be coordinated into a unique curve of the relative stress relief at the final point of the $i$-th cycle in each test, $\eta_{f, i}$, vs. the cumulative plastic strain prior to the onset of the $i$-th cycle, $\sum e_{p, i-1}$.

(2) This was experimentally justified by results of reloading stress relaxation tests on a $12 \mathrm{wt} \% \mathrm{Cr}$ type steel. Applying the unique curve of $\eta_{f, i} v s$. $\sum e_{p, i-1}$, constructed only from short period reloading data, it is possible to predict long period reloading stress relaxation behavior.

(3) The values of $Q$ computed from the experimental results were $75 \sim 95 \mathrm{kcal} / \mathrm{mol} \quad(314 \sim 397 \mathrm{~kJ} /$ $\mathrm{mol}$ ), being comparable to the apparent activation energy usually observed during creep in heat resisting steels.

\section{Acknowledgements}

The author acknowledges the assistance of Dr. R. Sasaki, Hitachi Research Lab. of Hitachi Ltd., pursuing the above research.

\section{REFERENCES}

1) J.H.M. Draper: Iron Steel, 34, (1961), 622.

2) A. Smith, D. J. Armstrong, M. F. Day and L.M.T. Hopkin: Joint Inter. Conf. on Creep, Sess. 6, London, (1963).

3) S. T. Quaass: J. Inst. Metals, 96 (1968), 129.

4) F. Suzuki: High Temperature Strength in Metallic Materials, ed. by S. Taira, Yokendo Book Co., Tokyo, (1968).

5) S. Taira and F. Suzuki: J. Soc. Mater. Sci., Japan, 11 (1962), 169.

6) T. Shinoda: Doctoral Thesis to Tokyo Institute of Technology, (1973).

7) Yu. N. Rabotnov: Creep Problems in Structural Members, English translation ed. by F. A. Leckie, North-Holland Pub. Co., Amsterdam-London, (1969), 210.

8) T. Shinoda and S. Sasaki: J. Soc. Mater. Sci. Japan, 16 (1967), 150.

9) A. Hede and B. Aronsson: JISI, 207 (1969), 1241. 